\title{
A Study on Consultant's Social Value, Learning, Leadership Type Influence on Consulting Flow and Performance
}

\author{
Choo Yang-Hyun ${ }^{1}$, Choo Soon-Jin ${ }^{1}, \&$ Lee Seung-Hee ${ }^{1}$ \\ ${ }^{1}$ Department of Consulting, Kumoh National Institute of technology, South of Korea \\ Correspondence: Choo Yang-Hyun. E-mail: cyhhd6420@naver.com
}

Received: April 13, 2018

Accepted: June 30, $2018 \quad$ Online Published: July 27, 2018

doi:10.5539/ass.v14n8p27

URL: https://doi.org/10.5539/ass.v14n8p27

\begin{abstract}
The purpose of this study is to investigate consultants in ongoing consulting projects for smaller enterprises to implement an empirical study on the degree of influence of consultant value, consultant learning and consultant leadership type on consulting performance, which have not been mentioned in preceding study. The surveyed were consultants who had provided consulting service to smaller enterprises. For the study, a total of 223 sets of questionnaires were collected but 18 poorly-answered sets were excluded to utilize 205 sets for the study research. As a summary of the results, the social responsibility had a significant effect on consulting Flow whereas social support did not. learning motivation, learning intention and transformational/transactional/servant leadership on consulting Flow found that all of the variables had a significant effect on consulting Flow. In addition to that, social responsibility, support and learning motivation, learning intention and transformational/transactional/servant leadership on consulting satisfaction found that all of the variables significantly affected consulting satisfaction.
\end{abstract}

Keywords: consultant, social value, learning, leadership, consulting flow, performance

\section{Introduction}

Recently, amid the expanding influence of smaller enterprises on society in South Korea, people become more interested in the nonfinancial performances of firms such as social or environmental issues. Company management continuously requires change $27 \mathrm{~s}$ in management goals, corporate culture, organizational structure and organizational members' attitude. In the process of corporate change management, the necessity for consulting is increasing. In this situation, consultants apply not only their knowledge and experiences but also ethical and moral standards to their advice and guidance for a variety of requirements from enterprises.

Preceding study on smaller enterprises found that, among the consultants' qualities, the levels of characteristics, knowledge, educational support, etc. had a positive effect on business performance (Kim \& Hwang, 2001; Bae, 2013; Yun, 2013). There is a growing realization of companies on social responsibility in the perspectives of growth and distribution, and there is an increasing tendency of focusing on the parties concerned as well as the parties involved with interest.

Consultants participate in diverse projects to achieve their consulting goals and, in the participation process, they need the sense of social responsibility and support such as moral recognition and model behavior.

Learning is defined as knowledge acquired through research, experience or study, or knowledge or skill gained through education or research (Oxford dictionaries). Consultants' knowledge is formed by learning and experiencing. To this end, they will need motivation, will, etc. Motivation and will for learning positively affect Flow (Won \& Lee, 2013) and influence smaller firms' performance by providing expertise in project management and operation (Nah et al., 2001, Thong et al., 1994, Yap et al., 1992).

In the consulting project process, consulting organizational leader or individual's ability has a great effect on achieving company performance goals or project goals. This is because the type of consulting organizational leadership and consultants' motivation affect work satisfaction (Hersey \& Blanchard, 1982). In light of this, it is expected that there will be difference in influence on consulting Flow and satisfaction depending upon consultants' social responsibility and support and their learning and leadership type and degree.

This study investigates consultants in ongoing consulting service for smaller enterprises and seeks to analyze difference in relationship affecting consulting Flow and satisfaction according to social responsibility and 
support, learning motivation and will, and leadership type, which have not been mentioned in preceding research. By doing so, the study aims at presenting a way for more practical approach.

\section{Theoretic Background and Study Hypothesis}

\subsection{Relationship between Consultant's Value and Consulting Flow, Consulting Performance}

We are making tremendous efforts for sustainable management of small and medium-sized businesses under the global environment, but we are facing many difficulties internally and externally. To overcome them, we are implementing small and medium-sized business consulting. Various consulting methods are applied such as diagnosis and strategy establishment to solve difficulties and problems of small and medium-sized businesses, and these are proved to have a positive effect on business performances. (The Small and Medium Business Administration of Korea, 2015)

McGuire (1963) conceptualized corporate social responsibility (CSR) activity as economic and legal obligations and even the responsibility for the society as a whole. Carroll (1979) divided corporate responsibilities specifically into economic, legal, ethical and charitable activities. Petkus and Woodruff (1992) defined the relationship between corporate social responsibility with Flow by minimizing harm to society while maximizing long-term contribution.

Social support can be separated into emotional support where one perceives he or she is receiving support from people around; evaluative support where one thinks he or she is fairly and properly evaluated for own work and attitude; and informational support where one feels he or she is loved, esteemed and respected based on causal relationship in a society (Ahn et al., 2011).

Jung gi-han (2007) the corporate social responsibility positively affects Flow and customer loyalty in terms of image, trust, Flow, and customer loyalty.

In the consulting industry, social support based on ethics is necessary because client firms' secrets known during project implementation should be kept confidential, no false result should be presented in consulting implementation, and project scope should not go beyond the specialty area. Based on these theoretical predictions and previous research, we set the following hypothesis.

H1: The value of consultant (social responsibility and social value) might have a positive effect on Flow.

1-1 consultant's social responsibility might have a positive effect on Flow.

1-2 consultant's social support might have a positive effect on Flow.

$\mathrm{H} 2$ : The value of consultant (social responsibility and social value) might have a positive effect on satisfaction

2-1 consultant's social responsibility might have a positive effect on satisfaction.

2-2 consultant's social support might have a positive effect on satisfaction.

\subsection{Relationship between Consultant's Learning and Consulting Flow, Consulting Performance}

Learning behaviors are the process of acquiring knowledge through communication with consultants, and the information and knowledge acquired in this process have a positive effect on organizational Flow. Won Yu-seok and Lee Jun-jae (2013) claim that business ability improvement through learning has a positive influence on organizational Flow. Park Sun-bong (2014) claims in a study on consultant's ethics and values that motive, sharing results and transparency affect Flow. Jang Dong-in (2011) reveals the responsibility relation that should be done while consulting is implemented such as ability, knowledge, will and attitude with social behaviors in a study on the component factors of management consultant's competence.

Kim Jae-hwan (2011) claims if the level of business educator's personal competence is high, job satisfaction is significantly high in the effect of business educator's personal competence on job satisfaction. This indicates as high group's personal competence is high, the level of effect that has on job satisfaction is high. This means consultant can enhance consulting satisfaction on the overall business.

Teece, Pisano and shuen (1997) stressed the necessity for learning a new capacity continuously to secure their competitiveness. For a successful consulting implementation, consultants should acquire knowledge on the sustained basis in addition to professional experiences. Consultants' knowledge is formed by learning and provides expertise in their project management and operation reportedly to influence smaller firms' performance (Nah et al., 2001; Thong et al., 1994; Yap et al., 1992).

Kim jae-hwan (2011) A consulting organization is made up of manpower who can apply and manage suitable methods for consulting purposes. With the input manpower, a person in charge of assignments is required to have 
knowledge to manage the whole project as well as core competences including leadership.

Myeongnam Jeon (2014) reported in his study on team learning and team effectiveness that learning motivation and learning support had a positive effect on team performance. It was found to have affected the relationship between learning behavior and leadership and have a strong interactivity with team learning and innovation performance. Given the study finding that consultant education positively influences management performance and satisfaction, consultants can secure their competitiveness by enhancing consulting organizational efficacy, consulting Flow and satisfaction in addition to their personal capacity building when they have the internal motivation to participate based on psychological improvement and voluntary efforts. Therefore, consultants can reinforce their own capacity based on learning motivation and will and it influences consulting Flow and satisfaction. Based on these theoretical predictions and previous research, we set the following hypothesis.

H3: Consultant's Learning (learning motivation and intension) might have a positive effect on Flow.

3-1 Consultant's learning motivation might have a positive effect on Flow.

3-2 Consultant's learning intension might have a positive effect on Flow.

H4: Consultant's Learning(learning motivation and intension) might have a positive effect on satisfaction.

4-1 Consultant's learning motivation might have a positive effect on satisfaction.

4-2 Consultant's learning intension might have a positive effect on satisfaction.

\subsection{Relationship between Consultant's Leadership and Consulting Flow, Consulting Performance}

A consulting organization is made up of manpower who can apply and manage suitable methods for consulting purposes. With the input manpower, a person in charge of assignments is required to have knowledge to manage the whole project as well as core competences including leadership.

The paradigm of leadership is changing into three types - transformational leadership, transactional leadership, and servant leadership. The transformational leadership (Burns, 1978) interacts with organizational members to boost up their interest and enthusiasm, seeks shared goals, presents a new vision and cares for individuals to motivate and induce Flow. The transactional leadership (Bass, 1985) is to motivate to achieve a goal by exchanges or performance and reward regarding what is mutually beneficial for a leader and organizational members. The servant leadership (Greenleaf, 1991), according to preceding leadership, has been developed with the main focus on ethicality and is developing into the areas of human respect, members' growth, morality and leadership exhibition after starting from the ideas of respect, volunteering, justice, honesty and community ethics (Laub, 1999). Against this backdrop, this study implements an empirical study under the assumption that the effect on consulting Flow and satisfaction would be different depending upon the leadership type of a leader responsible for a task in a project.

Consulting Flow and satisfaction factors are fundamental performance variables. Locke (1976) defined that work satisfaction is a pleasant or emotional status determined in organizational members' evaluation on their work. Min-ju Kim et al. (2013) emphasized to reinforce business performance capacity and expertise of a consulting firm to secure competitiveness. They presented it was possible through learning. In other words, consultants' knowledge, skill, and attitude factors have a positive effect on Flow and consulting performance.

Sunbong Park (2014) reported that consultants' perceived capacity level positively affected consulting satisfaction. Depending upon a consultant's personal characteristic and the levels of his or her perceived knowledge and attitude, Flow and satisfaction would vary. Based on these theoretical predictions and previous research, we set the following hypothesis.

H5: Consultant's Leadership (transformational leadership, transactional leadership, servant leadership) might have a positive effect on Flow.

5-1 Consultant's transformational leadership might have a positive effect on Flow.

5-2 Consultant's transactional leadership might have a positive effect on Flow.

5-3 Consultant's servant leadership might have a positive effect on Flow.

H6: Consultant's Leadership might have a positive effect on satisfaction.

6-1 Consultant's transformational leadership might have a positive effect on satisfaction.

6-2 Consultant's transactional leadership might have a positive effect on satisfaction.

6-3 Consultant's servant leadership might have a positive effect on satisfaction. 


\section{Empirical Study}

\subsection{Study Model and Hypothesis Setup}

The purpose of this study is to investigate consultants in ongoing consulting projects for smaller enterprises to implement an empirical study on the degree of influence of consultant value, consultant learning and consultant leadership type on consulting performance, which have not been mentioned in preceding study.

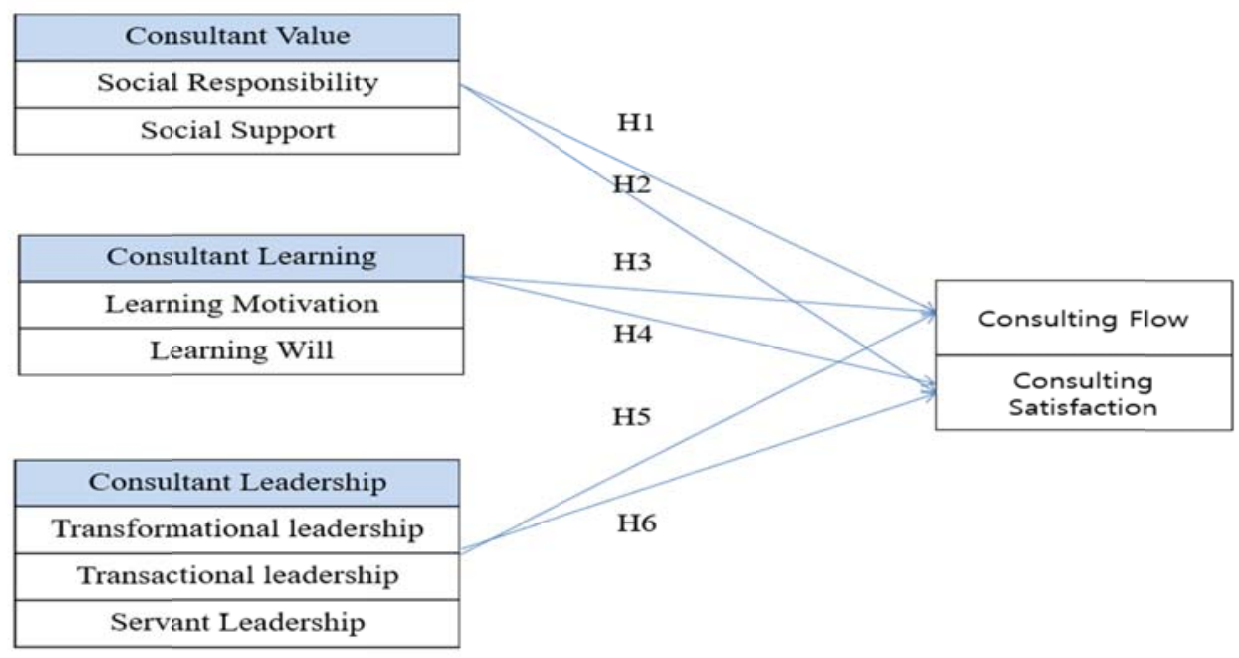

Figure 1. Study model

The aim of study model presented in Figure 1 is summarized as follows;

First, implement an empirical study on the effect of consultant value on consulting performance.

Second, implement an empirical study on the effect of consultant learning on consulting performance.

Third, implement an empirical study on the effect of consultant leadership type on consulting performance.

\subsection{Investigation Method}

\subsubsection{Study Subject and Analysis Method}

This study independently surveyed the sample for the total of 5 months from April 10 to July 9, 2016 and from June to August 1, 2017. The surveyed were consultants who had provided consulting service to smaller enterprises. For the study, a total of 223 sets of questionnaires were collected but 18 poorly-answered sets were excluded to utilize 205 sets for the study research.

\subsubsection{Analysis Method}

The data collected through survey were analyzed using SPSS 21.0 statistical package in the following steps;

First, to understand the general characteristics of overall consulting and consultants, descriptive statistical analysis was implemented. Such a descriptive statistical analysis was performed in order to better understand the representative characteristics of data distribution.

Second, since measurement items need to be selected and sophisticated before data analysis, validity and reliability analysis was conducted to this end.

Third, to empirically analyze the effect of each independent variable on the dependent variables of consulting Flow and satisfaction, multiple regression analysis was conducted

\subsection{Definition and Measurement of Variables}

\subsubsection{The Value of Consultant (Social Responsibility, Social Support)}

Based on research items, social responsibility is defined as "minimizing negative elements that affect a company and contributing to social growth in the long run", and measured to be items of efforts for company growth, company diagnosis, fair instruction, protection of client company and unestablishment of company's unfavorable plans on consumers.

Social support is defined as "respecting causal relationship in the society to receive fair and just evaluation", and measured with Likert 5 point scale on fair behavior, positive recognition, others' help and respecting personality. 


\subsubsection{Learning of Consultant (Learning Motivation, Learning Will)}

Based on the study, learning motivation is defined as "power that causes behaviors for a certain goal" and measured with being helpful to consulting implementation, mathematical/statistical knowledge acquisition, supplementary education and problem solving ability.

Learning will is defined as "the attitude of actively participating in learning process such as learning new things and applying the learned things to actual situations" and measured on necessary knowledge, learning method, time investment, interested contents and learning understanding.

\subsubsection{Consultant Leadership Types}

Based on the study, transforming leadership is defined as "the leadership that rationally presents compensation, clear goal and direction" and such items as accomplishment method of new perspective, presentation of strategy and goal, presentation of ability and confidence, and presentation of expansive idea are measured. Transactional leadership is defined as "the leadership that obeys legal conditions and various regulations by necessity of concerns and calculating interest", and measured with compensation according to accomplishment of goal, degree of effort and case of falling short of goal level. Servant leadership is defined as "the leadership that shares goals, promotes growth, forms trust among one another and makes organizational performance accomplished" and such items as trust to colleagues, reaction to member's demand and listening to suggestions are measured.

\subsubsection{Performance of Consultant}

Based on the study, consulting Flow is defined as "participating in consulting by committing himself or herself" and measured with preparation for professional consultant, many efforts, job attachment and perfect job performance.

Consulting satisfaction is defined as "performing consulting as occupation and being satisfied financially and mentally" and measured on lifelong occupation, current job satisfaction and job value.

\section{Empirical Analysis}

\subsection{Reliability Analysis}

The result of reliability analysis in Table 1 . shows all variables are over 0.661 and have fine internal consistency.

Table 1. Reliability Analysis

\begin{tabular}{ccc}
\hline Variables & Number of Qestions & Cronbach's $a$ \\
\hline Social responsibility & 3 & .679 \\
Social support & 4 & .851 \\
Learning motivation & 5 & .673 \\
Learning will & 5 & .856 \\
Transformational leadership & 4 & .724 \\
Transactional leadership & 3 & .661 \\
Servant leadership & 3 & .742 \\
Consulting Flow & 4 & .869 \\
Consulting satisfaction & 3 & .829 \\
\hline
\end{tabular}

\subsection{Validity Analysis}

For the factor analysis in Table 2, principle component analysis is used, and for easy explanation of item reduction and each factor, orthogonal rotation is applied. The result is as follows.

Table 2. Validity Analysis

\begin{tabular}{ccccccccc}
\hline Variables & \multicolumn{10}{c}{ Factors } \\
\cline { 2 - 8 } & 1 & 2 & 3 & 4 & 5 & 6 & 7 & 8 \\
\hline Responsibility 1 & .564 & & & & & & \\
Responsibility 2 & .526 & & & & & & \\
Responsibility 4 & .854 & & & & & \\
Social support 1 & & .610 & & & & \\
Social support 2 & & .871 & & & & & \\
Social support 3 & & .784 & & & & & \\
\hline
\end{tabular}




\begin{tabular}{|c|c|c|c|c|c|c|c|c|c|}
\hline Social support 4 & & .881 & & & & & & & \\
\hline Motivation 1 & & & .715 & & & & & & \\
\hline Motivation 2 & & & .663 & & & & & & \\
\hline Motivation 3 & & & .525 & & & & & & \\
\hline Motivation 4 & & & .781 & & & & & & \\
\hline Motivation 5 & & & .711 & & & & & & \\
\hline Learning will 1 & & & & .675 & & & & & \\
\hline Learning will 2 & & & & .742 & & & & & \\
\hline Learning will 3 & & & & .874 & & & & & \\
\hline Learning will 4 & & & & .713 & & & & & \\
\hline Learning will 5 & & & & .821 & & & & & \\
\hline Transformational 1 & & & & & .715 & & & & \\
\hline Transformational 2 & & & & & .784 & & & & \\
\hline Transformational 3 & & & & & .520 & & & & \\
\hline Transformational 4 & & & & & .888 & & & & \\
\hline Transactional 1 & & & & & & .579 & & & \\
\hline Transactional 2 & & & & & & .518 & & & \\
\hline Transactional 3 & & & & & & .822 & & & \\
\hline Servant 1 & & & & & & & .747 & & \\
\hline Servant 2 & & & & & & & .850 & & \\
\hline Servant 3 & & & & & & & .636 & & \\
\hline Flow 1 & & & & & & & & .863 & \\
\hline Flow 2 & & & & & & & & .724 & \\
\hline Flow 3 & & & & & & & & .865 & \\
\hline Flow 4 & & & & & & & & .627 & \\
\hline Satisfaction 1 & & & & & & & & & .750 \\
\hline Satisfaction 2 & & & & & & & & & .719 \\
\hline Satisfaction 3 & & & & & & & & & .839 \\
\hline Eigenvalue & 5.817 & 3.360 & 3.227 & 2.449 & 2.331 & 2.207 & 2.191 & 1.992 & 1.898 \\
\hline$\%$ of Variance & 17.108 & 9.882 & 9.492 & 7.202 & 6.855 & 6.491 & 6.445 & 5.858 & 5.583 \\
\hline Cumulative \% & 17.108 & 26.990 & 36.481 & 43.684 & 50.539 & 57.029 & 63.474 & 69.332 & 74.915 \\
\hline
\end{tabular}

\subsection{Hypothesis Verification}

By following the factor analysis steps above, the number of variables was reduced to identify 9 meaningful factors. Factor scores derived from factor analysis were designated to be saved. Factor scores were gained from regression analysis with 7 independent variables for regression/discriminant analyses (support, will, responsibility, motivation, transformation, servant, and transaction) and 2 dependent variables.

When this method is chosen, the problem of potential insignificance of many independent variables due to the multicollinearity among independent variables can be resolved to enable more significant analysis

Table 3. Relationship between consultants' social responsibility, support and Flow

\begin{tabular}{|c|c|c|c|c|c|c|c|c|}
\hline & \multirow[t]{2}{*}{ Model } & \multicolumn{2}{|c|}{$\begin{array}{c}\text { Non-standardized } \\
\text { coefficient }\end{array}$} & \multirow{2}{*}{$\begin{array}{c}\text { Standardized } \\
\text { coefficient }\end{array}$} & \multirow[t]{2}{*}{$\mathrm{t}$} & \multirow{2}{*}{$\begin{array}{l}\text { Significance } \\
\text { probability }\end{array}$} & \multicolumn{2}{|c|}{$\begin{array}{c}\text { Collinearity } \\
\text { statistics }\end{array}$} \\
\hline & & $\mathrm{B}$ & standard error & & & & Allowance & VIF \\
\hline \multirow{3}{*}{1} & (constant) & .147 & .468 & & .313 & .754 & & \\
\hline & responsibility & .697 & .085 & .492 & 8.191 & .000 & .994 & 1.006 \\
\hline & support & .186 & .073 & .152 & 2.540 & .012 & .994 & 1.006 \\
\hline$R^{2}$ & .277 & & & & & & & \\
\hline F-value & $38.659 * * *$ & & & & & & & \\
\hline$* \mathrm{p}<0$ & $* * \mathrm{p}<0$ & & $* \mathrm{p}<0.01$ & & & & & \\
\hline
\end{tabular}


The multiple regression analysis result shows that regression model is 38.659 in $\mathrm{F}$ statistics $\mathrm{p}=.000$, and $R^{2}=.277$ for regression equation. The explanation power is $27 \%$. Social responsibility of consultant $(t=8.191, p<0.01)$ affects consulting Flow, and social support $(\mathrm{t}=2.540, \mathrm{p}>0.1)$ has an insignificant effect on consulting Flow.

Table 4. Relationship between consultants' learning motivation, will and Flow

\begin{tabular}{|c|c|c|c|c|c|c|c|c|}
\hline \multirow{2}{*}{\multicolumn{2}{|c|}{ Model }} & \multicolumn{2}{|c|}{$\begin{array}{c}\text { Non-standardized } \\
\text { coefficient }\end{array}$} & \multirow{2}{*}{$\begin{array}{c}\text { Standardized } \\
\text { coefficient }\end{array}$} & \multirow[t]{2}{*}{$\mathrm{t}$} & \multirow{2}{*}{$\begin{array}{l}\text { Significance } \\
\text { probability }\end{array}$} & \multicolumn{2}{|c|}{$\begin{array}{l}\text { Collinearity } \\
\text { statistics }\end{array}$} \\
\hline & & B & standard error & & & & Allowance & VIF \\
\hline \multirow{3}{*}{1} & (constant) & -.432 & .510 & & -.847 & .398 & & \\
\hline & Motivation & .768 & .122 & .404 & 6.277 & .000 & .851 & 1.175 \\
\hline & Will & .258 & .073 & .227 & 3.531 & .001 & .851 & 1.175 \\
\hline$R^{2}$ & .286 & & & & & & & \\
\hline F-value & $40.516^{* * *}$ & & & & & & & \\
\hline$* \mathrm{p}<0$. & $* * \mathrm{p}<$ & .05 & $* * * \mathrm{p}<0.01$ & & & & & \\
\hline
\end{tabular}

The multiple regression analysis result shows that regression model is 40.516 in $\mathrm{F}$ statistics $\mathrm{p}=.000$, and $R^{2}=.286$ for regression equation. The explanation power is $28 \%$. Learning motivation $(\mathrm{t}=6.277, \mathrm{p}<0.01)$ and learning Will $(\mathrm{t}=3.531, \mathrm{p}<0.05)$ affects consulting Flow.

Table 5. Relationship between consultant leadership type and Flow

\begin{tabular}{|c|c|c|c|c|c|c|c|c|}
\hline & \multirow[t]{2}{*}{ Model } & \multicolumn{2}{|c|}{$\begin{array}{l}\text { Non-standardized } \\
\text { coefficient }\end{array}$} & \multirow{2}{*}{$\begin{array}{c}\text { Standardized } \\
\text { coefficient }\end{array}$} & \multirow[t]{2}{*}{$\mathrm{t}$} & \multirow{2}{*}{$\begin{array}{l}\text { Significance } \\
\text { probability }\end{array}$} & \multicolumn{2}{|c|}{$\begin{array}{c}\text { Collinearity } \\
\text { statistics }\end{array}$} \\
\hline & & $\mathrm{B}$ & standard error & & & & Allowance & VIF \\
\hline \multirow{4}{*}{1} & (constant) & 1.163 & .497 & & 2.339 & .020 & & \\
\hline & Transformational & .570 & .106 & .347 & 5.378 & .000 & .893 & 1.120 \\
\hline & Transactional & .411 & .090 & .297 & 4.577 & .000 & .886 & 1.128 \\
\hline & Servant & -.260 & .079 & -.210 & -3.298 & .001 & .920 & 1.087 \\
\hline$R^{2}$ & .251 & & & & & & & \\
\hline F-value & $22.463 * * *$ & & & & & & & \\
\hline$<0$ & $* * \mathrm{p}<0.05$ & & 0.01 & & & & & \\
\hline
\end{tabular}

The multiple regression analysis result shows that regression model is 22.463 in $\mathrm{F}$ statistics $\mathrm{p}=.000$, and $R^{2}=.251$ for regression equation. The explanation power is $25 \%$. Transformational leadership $(\mathrm{t}=5.378, \mathrm{p}<0.01)$, Transactional leadership $(\mathrm{t}=4.577, \mathrm{p}<0.01)$ and Servant leadership $(\mathrm{t}=3.531, \mathrm{p}<0.05)$ affects consulting Flow.

Table 6. Relationship between consultants' social responsibility, support and satisfaction

\begin{tabular}{|c|c|c|c|c|c|c|c|c|}
\hline & \multirow[t]{2}{*}{ Model } & \multicolumn{2}{|c|}{$\begin{array}{c}\text { Non-standardized } \\
\text { coefficient }\end{array}$} & \multirow{2}{*}{$\begin{array}{c}\text { Standardized } \\
\text { coefficient }\end{array}$} & \multirow[t]{2}{*}{$\mathrm{t}$} & \multirow{2}{*}{$\begin{array}{l}\text { Significance } \\
\text { probability }\end{array}$} & \multicolumn{2}{|c|}{$\begin{array}{c}\text { Collinearity } \\
\text { statistics }\end{array}$} \\
\hline & & B & standard error & & & & Allowance & VIF \\
\hline \multirow{3}{*}{1} & (constant) & -.643 & .533 & & -1.207 & .229 & & \\
\hline & Responsibility & .833 & .097 & .510 & 8.596 & .000 & .994 & 1.006 \\
\hline & support & .211 & .083 & .150 & 2.531 & .010 & .994 & 1.006 \\
\hline$R^{2}$ & .182 & & & & & & & \\
\hline F-value & $22.484 * * *$ & & & & & & & \\
\hline$* \mathrm{p}<0$ & $* * \mathrm{p}<0$ & & $\mathrm{p}<0.01$ & & & & & \\
\hline
\end{tabular}

The multiple regression analysis result shows that regression model is 22.484 in F statistics $\mathrm{p}=.000$, and $R^{2}=.182$ for regression equation. The explanation power is $18 \%$. Social responsibility of consultant $(t=8.596, p<0.01)$ and social support $(\mathrm{t}=2.531, \mathrm{p}<0.1)$ affects consulting Flow. 
Table 7. Relationship between consultants' learning motivation, will and satisfaction

\begin{tabular}{|c|c|c|c|c|c|c|c|c|}
\hline \multirow{2}{*}{\multicolumn{2}{|c|}{ Model }} & \multicolumn{2}{|c|}{$\begin{array}{c}\text { Non-standardized } \\
\text { coefficient }\end{array}$} & \multirow{2}{*}{$\begin{array}{c}\begin{array}{c}\text { Standardized } \\
\text { coefficient }\end{array} \\
\text { beta }\end{array}$} & \multirow[t]{2}{*}{$\mathrm{t}$} & \multirow{2}{*}{$\begin{array}{c}\text { Significance } \\
\text { probability }\end{array}$} & \multicolumn{2}{|c|}{$\begin{array}{l}\text { Collinearity } \\
\text { statistics }\end{array}$} \\
\hline & & B & standard error & & & & Allowance & VIF \\
\hline \multirow{3}{*}{1} & (constant) & -.181 & .630 & & -.287 & .775 & & \\
\hline & Motivation & .728 & .151 & .333 & 4.822 & .000 & .851 & 1.175 \\
\hline & will & .220 & .090 & .168 & 2.438 & .016 & .851 & 1.175 \\
\hline$R^{2}$ & .286 & & & & & & & \\
\hline F-value & $40.516^{* * *}$ & & & & & & & \\
\hline
\end{tabular}

The multiple regression analysis result shows that regression model is 40.516 in $\mathrm{F}$ statistics $\mathrm{p}=.000$, and $R^{2}=.286$ for regression equation. The explanation power is $28 \%$. Learning motivation $(\mathrm{t}=4.822, \mathrm{p}<0.01)$ affects consulting Flow. whereas learning will $(\mathrm{t}=2.438, \mathrm{p}>0.1)$ had an insignificant effect on consulting satisfaction In addition, the tolerance limit and VIF were checked and they showed no multicollinearity

Table 8. Relationship between consultants' leadership type and satisfaction

\begin{tabular}{|c|c|c|c|c|c|c|c|c|}
\hline & \multirow[t]{2}{*}{ Model } & \multicolumn{2}{|c|}{$\begin{array}{c}\text { Non-standardized } \\
\text { coefficient }\end{array}$} & \multirow{2}{*}{$\begin{array}{c}\text { Standardized } \\
\text { coefficient }\end{array}$} & \multirow[t]{2}{*}{$\mathrm{t}$} & \multirow{2}{*}{$\begin{array}{l}\text { Significance } \\
\text { probability }\end{array}$} & \multicolumn{2}{|c|}{$\begin{array}{c}\text { Collinearity } \\
\text { statistics }\end{array}$} \\
\hline & & B & standard error & & & & Allowance & VIF \\
\hline \multirow{4}{*}{1} & (constant) & 2.134 & .571 & & 3.741 & .000 & & \\
\hline & Transformational & .659 & .122 & .348 & 5.415 & .000 & .893 & 1.120 \\
\hline & Transactional & .339 & .103 & .212 & 3.291 & .001 & .886 & 1.128 \\
\hline & Servant & -.547 & .091 & -.383 & -6.044 & .000 & .920 & 1.087 \\
\hline$R^{2}$ & .259 & & & & & & & \\
\hline F-value & $23.388 * * *$ & & & & & & & \\
\hline$"$ & $* * \mathrm{p}<0.05$ & & 0.01 & & & & & \\
\hline
\end{tabular}

The multiple regression analysis result shows that regression model is 23.388 in F statistics $\mathrm{p}=.000$, and $R^{2}=.259$ for regression equation. The explanation power is $25 \%$. Transformational leadership $(t=5.415, p<0.01)$, Transactional leadership $(\mathrm{t}=3.291, \mathrm{p}<0.05)$ and Servant leadership $(\mathrm{t}=--6.044, \mathrm{p}<0.01)$ affects consulting Flow.

\section{Conclusion}

\subsection{Study Summary and Implications}

This study examined consultants providing consulting service to smaller enterprises who had not been mentioned in preceding study for the purpose to examine difference in effect on consulting Flow and satisfaction according to the consultant value of social responsibility and support, learning motivation and will, and leadership types of transformational/transactional/servant leadership. Based on the analysis, this study seeks to present a way for practical approach.

To achieve such a study purpose, preceding literature was examined to identify the independent variables of social responsibility and support, learning motivation and will, leadership variables of transformational/transactional/servant leadership as well as dependent variables of consulting Flow and satisfaction; and their relationships were analyzed.

The analysis results are summarized as follows;

First, the analysis on the effect of consultants' social responsibility and support on consulting Flow found that the social responsibility had a significant effect on consulting Flow whereas social support did not. Such a finding indicates that consultants' social responsibility such as efforts for corporate growth, fairness in consulting instruction and company data protection affect consulting Flow such as attachment for consulting implementation and efforts as a professional consultant. On the other hand, evaluation on surrounding people, recognition, assistance, and respect were found to have no effect on consulting Flow. It seems because most consultants provide their consulting service by focusing on CEOs and executives thus, other people's evaluation has no effect. Therefore, the government agency should adopt a system that consultants complete consulting 
education programs as a method for consulting Flow through improvement of consultants' social responsibility.

Second, in the result of analyzing the effects of consultants' social responsibility and support on consulting satisfaction, both social responsibility and support have a significant effect on consulting satisfaction. When the importance level of variables' sub-factors is understood, social responsibility has a stronger impact on consulting satisfaction than social support does.

Thus, public institutions need to eradicate wrongful use of government grants to companies as a method to improve consultants' social responsibility and support.

Third, in the result of analyzing the effects of consultants' learning motivation and learning will on consulting satisfaction and Flow, both variables have a positive effect on consulting satisfaction and Flow. This indicates that government support agencies need to supply systemic education programs that provide professional knowledge necessary for consulting implementation, and for the growth of overall consulting industry, it is necessary to adopt programs in connection with domestic universities and consulting graduate schools such as MBA.

Fourth, in the relation of consulting Flow with consultants' transforming leadership, transactional leadership and servant leadership, transactional leadership is the most influential followed by transforming leadership and servant leadership. Especially, consultants' transactional leadership is motivation related to actual income, so it is more influential. It is necessary to establish a profit creation plan for improvement of beginner consultants' Flow.

Fifth, consultants' transforming leadership, transactional leadership and servant leadership have a significant effect on consulting satisfaction. Especially, transforming leadership instills their own value according to the changes of consulting situations when they perform consulting tasks, so it can be considered as more important leadership for effective consulting management. Therefore, to promote the above leaderships, it is important to develop and apply methods suitable for the purposes of consulting and to consider input consultants' competencies, relevant fields of projects, dimension and difficulty levels for effective management.

\subsection{Study Limitation and Future Plan}

This study examined the effect on consulting Flow and satisfaction of social responsibility and support from an ethical perspective of consultants providing consulting service to smaller firms, of learning motivation and will to reinforce individual capacity and of the leadership type of a leader in a consulting project.

This study seems meaningful in working to differentiate itself from preceding studies. Nevertheless, the study has limitations as follows:

First, the study may have the limitation of non-sampling error as the independent variables such as morality, ethical aspect, personal capacity aspect and leadership type were analyzed and selected based on the researcher's own assessment.

Second, results may become different depending upon a consultant's age, experience, and specialized area of consulting. In this sense, the study is not free of non-sampling error.

Third, based on the results above, regulation effect analysis was implemented to verify the gap in effect sizes among the sub-groups. But $75 \%$ were found not statistically significant. This unveils the limitation of this study regarding the relationship between interaction effect where both independent variables and regulation variables show influence altogether and main effect where they show influence separately.

Due to the three limitations above, generalization of study findings may be limited. In this sense, additional study seems necessary.

In terms of study methodology, it is suggested to utilize experimental designing in test, rather than survey questionnaires. Also, if focus group interview (FGI) or in-depth interview are employed for survey data collection, more reliable results would be produced.

Before closing, to enhance the reliability of survey-based research, future study will need to increase the number of survey questionnaires, move beyond the multiple regression analysis to investigate the influencing relationship by regulation effect, and examine the relationship among potential variables.

\section{References}

An, H.-m., \& Yang, H.-g. (2011). Research Articles: The Impact of Hotel Employees' Social Support on the Self-Efficacy and Helplessness. Journal of the Korean Food Service Association, 5(2), 53-69.

Bass, B. M. (1985). Leadership and Performance beyond Expectation. N.Y.: The Free Press. 
Carroll, A. B. (1979). A Three Dimensional Conceptual Model of Corporate Social Performance. Academy of Management of Review, 4(4), 497-505. https://doi.org/10.5465/amr.1979.4498296

Choi, B.-h. (2014). The effects of hotel F\&B employee's perceived social supports on motivation and organizational Flow. Food Service Industry Journal, 10(4), 111-123.

Greenleaf, R. K. (1991). The Servant as Leader. Indianapolis: The Greenleaf Center.

Jang, D.-I. (2011). Research on How Consultant's Capability and Competency Influence on Upgraded Service Quality and Customer Satisfaction (Master's Thesis). Kyunghee University.

Jeon, M.-n. (2014). The Mediating Effect of Team Shared Mental Model in the Relationship between Team Learning Behavior and Team Effectiveness in the College Classroom. Korea Industrial Education Institute, 28.

Jeong, G.-h. et al. (2007). Study on The Relationship among the Factors of Corporate Social Responsibility, Corporate Image, Relationship Quality, and Customer Loyalty. Korean Academic Society of Business Administration, 8, 1-14.

Kim, E.-s. (2013). Health Insurance Review Nurses' Organizational Flow Management Strategy for Improvement of Professional Self-concept and Social Support (Master's Thesis). Graduate School of Health and Welfare, CHA University.

Kim, J.-H. (2011). Effect of HRD Employee's Competency on the Job Satisfaction (Master's Thesis). Dankook University.

Kim, M.-j., Bae, E.-g., \& Kim, D.-y. (2013). HRD Consultant's Leader-The Mediating Effects of Informal Learning Activity on the Relationship between HRD Consultants' Leader-Member Exchange and Career Flow. Korean Journal of Business Administration, 1865-1885.

Laub, A. J. (1999). Assessing the servant organization: Development of the servant organizational leadership assessment (SOLA) instrument. Florida Atlantic University.

Lee, I.-s. (2014). Motives, partner selection criteria, and alliance capabilities of consulting firms in strategic alliances: Their effects on performance (Doctoral Thesis). Hansung University.

Locke, E. A. (1976). The nature and cause of job satisfaction. In M. D. dunnette (Ed.), Handbook of industrial and organizational psychology (pp. 1297-1349). Chicago: Rand McNally College Publishing Co.

Ma, S.-c. (2015). The Effect of Team Learning Behavior and Team Efficacy on Team Performance (Master's Thesis). Gachon University.

McGuire, J. (1963). Business and Society. New York.

Park, S.-B. (2014). A Study on Influence of Consultant's Perceived Competency Level on Their Job Satisfaction, Job Involvement, Turnover Will (Master's Thesis). Hansung University.

Petkus, Jr. E., \& Woodruff, R. B. (1992). A Model of the Socially Responsible Decision Making Process in Marketing: Linking Decision Makers and Stakeholders. Marketing Theory and Application, 3, 154-161.

Seok, B.-I. (2014). A Study on the Effect of Exchanging Relation Between the Leader and Members on Teamwork, Job Satisfaction (Doctoral Thesis). Seokyeong University.

Teece, D. J., Pisano, G., \& Shuen, A. (1997). Dynamic capabilities and strategic management. Strategic Management Journal, 18(7), 509-533. https://doi.org/10.1002/(SICI)1097-0266(199708)18:7<509::AIDSMJ882>3.0.CO;2-Z

Won, Y.-S., \& Lee, J.-J. (2013). Effects of Hotel Restaurant Employees' Motivation and Organizational Flow on the Efficacy. Journal of Tourism and Leisure Research, 25(6), 263-277.

\section{Copyrights}

Copyright for this article is retained by the author(s), with first publication rights granted to the journal.

This is an open-access article distributed under the terms and conditions of the Creative Commons Attribution license (http://creativecommons.org/licenses/by/4.0/). 